\title{
Underreporting of energy intake in repeated 24-hour recalls related to gender, age, weight status, day of interview, educational level, reported food intake, smoking habits and area of living
}

\author{
Gunnar Johansson ${ }^{1, *}$ Åsa Wikman ${ }^{1}$, Ann-Mari Åhrén², Göran Hallmans ${ }^{2}$ and \\ Ingegerd Johansson ${ }^{2,3}$ \\ 'Department of Food and Nutrition, University of Umeå, SE-901 87 Umeå, Sweden: ${ }^{2}$ Department of Public Health \\ and Clinical Medicine/Nutritional Research, University of Umeå, SE-901 87 Umeå, Sweden: ${ }^{3}$ Department of \\ Odontology/Cariology, University of Umeå, SE-901 87 Umeå, Sweden
}

Submitted 18 September 2000: Accepted 9 January 2001

\begin{abstract}
Objective: The aims of the present study were (1) to evaluate the degree to which underreporting of energy intake by repeated 24-hour recalls was related to gender, age, weight status, day of interview, educational level, smoking habits and area of living, and (2) to compare the dietary characteristics of underreporters with those of others.

Design: Cross-sectional study. Ten 24-hour recalls were performed during a one-year period.

Setting: The Västerbotten intervention programme of cardiovascular disease and diabetes in Northern Sweden.

Subjects: Ninety-four men and 99 women in four age groups: 30, 40, 50 and 60 years. Results: The prevalence of men and women with a food intake level (FIL; reported energy intake divided by estimated basal metabolic rate) below 1.2 was $44 \%$ and $47 \%$, respectively. The youngest age group had higher FIL values than the oldest age group for both men (1.5 versus 1.1) and women (1.4 versus 1.1). The prevalence and magnitude of underreporting were directly related to body mass index (BMI; correlation coefficient: -0.47 (men) and -0.55 (women)). Smokers had a lower FIL value (1.1) than non-smokers (1.3). The nutrient density was lower for the group with high FIL values for protein and calcium and higher for fat and sucrose. The upper FIL group often had higher intake frequencies and larger portion sizes than the lower FIL group.

Conclusions: Underreporting of energy intake is prevalent when 24-hour recalls are used, but the prevalence differs between sub-groups in the population. BMI was the main predictor of underreporting but also old age and smoking seem to contribute in this aspect. Socially desirable food items were not underreported to the same extent as socially undesirable food items. The intake frequencies and portion sizes partly explained the differences in FIL.
\end{abstract}

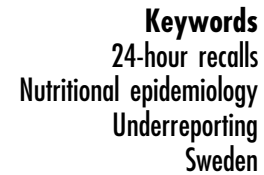

Keywords epidemiology Sweden
Underreporting of food intake is a commonly documented problem, which can seriously distort the interpretation of results from dietary surveys ${ }^{1-8}$. Many factors, such as physiological factors (for instance age and body weight ${ }^{3-8}$ ) and psychological factors (such as concern about diet and body weight ${ }^{9-13}$, social desirability and inter-personal distrust $^{14,15}$ ), may affect the ability and willingness to report various foods. A differential underreporting of various food items in relation to the total food intake makes the interpretation of epidemiological studies of diet and health complicated, and unevenly biased reporting within the population disturbs identification of the dietary influence on health and disease ${ }^{16}$. Several publications indicate lifestyle factors to be associated with dietary habits, such as smokers having different eating habits from non-smokers ${ }^{8,17-20}$. However, besides the described relation between obesity and systematic underreporting ${ }^{21}$, limited knowledge exists on how or if 
lifestyle factors bias reporting of food intake, such as whether smokers and non-smokers report food intake in the same manner. A more thorough knowledge on factors biasing food recording would be a step towards improving instruments for dietary assessment and possibly the design of studies evaluating diet-disease relationships.

Black et al. categorised underreporting by dietary assessment method and found that 64\%,88\% and 25\% of the results fell below an acceptable cut-off value using diet records, diet recall and diet history, respectively ${ }^{22}$. These data indicate that dietary assessment methods have a strong bias towards underestimation of habitual dietary intake and this is especially true for diet recall, where nine out of 10 surveys were not plausible.

The aims of the present study were to evaluate the prevalence of underreporting of energy intake in a Northern Swedish population, and to compare the dietary characteristics of underreporters and others.

\section{Material and methods}

\section{Subjects}

For the present study a sub-sample of the individuals attending the Västerbotten County Cardio Vascular Disease (CVD) Study ${ }^{23}$ in 1992 was randomly selected. A request to participate in the study, along with a description of the study and the names of the interviewers, was mailed to the selected men and women. A few days later they were called by one of the interviewers and participation confirmed. In total, 246 individuals were invited to participate but 43 declined due to lack of time for the interviews. Eight people did not complete the dietary interviews and two lacked information on body weight. Thus, 94 men and 99 women, equally distributed over the ages of 30, 40, 50 and 60 years, were included (Table 1). The participants were recruited in equal proportions from the coastal (urban, i.e. Umeå) and the inland/mountain (rural) areas of Västerbotten County. All participants had been screened for height and weight and CVD risk factors, such as total cholesterol, blood pressure, obesity and blood glucose, within the Västerbotten CVD Study.

The study was approved by the Ethics Committee for Human Experiments at Umeå University.

\section{Repeated 24-bour recalls}

Full size illustrations ${ }^{24}$ (produced by the National Food Administration, Uppsala, Sweden), including five options for portions of food on a plate, five options for spread on a knife, and a set of schematic drawings $(n=38)$, were used to indicate thickness and sizes of various types of food item. These illustrations were referred to during the interviews as a support to estimate the amounts eaten. Household measures were used for food items not included in the handout. Each respondent was interviewed over the telephone about their intake of food, 
beverages and supplements during the preceding day on 10 unannounced occasions. On average each interview lasted 15-20 minutes. The 10 interviews were equally spread over the year (January 1993 to January 1994) and all weekdays were represented. Local food traditions exist in the study area and therefore careful efforts were made to describe recipes and cooking style. Two of the interviewers, a nutritionist and a dietician, who worked closely together, coded the 24-hour recalls. Energy and nutrient intake was calculated using the software MAT's (Rudans Lättdata, Sweden) and the database from the National Food Administration ${ }^{25}$. Frequencies of intakes of single food items as well as recorded portion sizes were extracted from MAT's based on food item or food group codes.

\section{Assessment of lifestyle variables}

Data on gender, age, area of living and lifestyle variables were obtained within the framework of the Västerbotten CVD Study $^{23}$. The respondents answered a questionnaire including questions on smoking habits, educational level and physical activity. The participants were classified into a low or high educational level (less than 10 years in school and 10 years or more, respectively).

\section{Evaluation of underreporting}

Underreporting was based on an evaluation of food intake level (FIL) ${ }^{2}$, which is reported energy intake divided by predicted basal metabolic rate (EI/BMR), in relation to a plausible physical activity level $(\mathrm{PAL})^{26}$, which is the ratio of energy expenditure divided by predicted basal metabolic rate (EE/BMR). BMR was predicted from equations based on age, sex and body weight $^{27}$. PAL and FIL should be of the same value, if there is a true energy intake, given that the estimation of the energy expenditure is right. The FIL cut-off level chosen in this study was 1.2 , which corresponds to a PAL for a chair-bound or bed-bound person (survival limit) ${ }^{28}$.

The other FIL cut-off level used was 1.35. This is the former Goldberg cut-off 1 level $^{29}$, which is no longer recommended $^{30}$. However, in the absence of good estimates of energy expenditure, this arbitrary value is used. It is still true that PAL $=1.35$ is the mean value of people staying in calorimeters and reflects a PAL value of an extremely sedentary lifestyle ${ }^{29}$.

The difference in intake frequencies was calculated as follows: number of intakes of food items by the group with FIL $<1.2$ minus the number of intakes by the group with FIL $\geq 1.2$ divided by the number of intakes by the group with FIL $\geq 1.2$, expressed as a percentage (Table 5). Calculations were made with the use of one decimal digit. Only differences equal to or above $10 \%$ were taken into consideration.

\section{Statistical analysis}

Statistical analyses were carried out using the Statistical
Analyses System (SAS Inst., Carry, MO, USA) and SPSS software (Chicago, IL, USA). Univariate analyses of differences between mean values were done with analysis of variance (ANOVA), and Pearson correlations between FIL and body mass index (BMI) were calculated. When the ANOVA indicated a difference among the groups or when two groups were compared, a multiple mean test (two-sided Tukey's test) was applied. Differences between portions were tested by the chi ${ }^{2}$ test. Multivariate evaluation of the simultaneous effect of gender, age, BMI, education level, smoking and area of living on recorded food intake level was performed by a stepwise multiple linear regression. $P$ values below 0.05 were used as indication of statistical significance.

\section{Results}

Food intake (10 repeated 24-hour recalls per person) and body weights were monitored in 193 randomly selected 30-, 40-, 50- and 60-year-old respondents in Northern Sweden (Table 1). Average reported energy intake for men was 9.2 MJ day ${ }^{-1}$ (2192 $\mathrm{kcal} \mathrm{day}^{-1}$ ) (ranging from 4.6 to $16 \mathrm{MJ} \mathrm{day}^{-1}$ ), and for women was $6.9 \mathrm{MJ} \mathrm{day}^{-1}$ $\left(1642 \mathrm{kcal} \mathrm{day}^{-1}\right.$ ) (ranging from 3.1 to $12.4 \mathrm{MJ} \mathrm{day}^{-1}$ ). Reported energy intakes were evaluated for credibility versus underreporting in relation to two cut-off limits for FIL (Table 2). When FIL $<1.2$ was applied as cut-off limit, the prevalence of underreporting was $44 \%$ and $47 \%$ for men and women, respectively, whereas the cut-off limit FIL $<1.35$ would classify $61 \%$ of men and $72 \%$ of women as underreporters.

\section{Age, BMI and lifestyle associations with under- reporting}

Age, BMI and smoking were significantly associated with underreporting of food intake (Fig. 1). Thus, the average FIL was significantly higher for 30-year-olds than for 40-, 50- and 60-year-olds, but did not differ among the 40-, 50and 60-year-olds (Fig. 1); 26\%, 58\%, 45\% and 54\% among 30-, 40-, 50- and 60-year-olds, respectively, underreported $(P<0.01)$ (Table 2$)$. This pattern was largely the same when the genders were evaluated separately (Table 1).

Both men and women displayed a negative correlation between BMI and FIL (correlation coefficient: -0.47 and -0.55 , respectively, both $P<0.001$; Figs. 2(a) and (b)). Thus, FIL averages decreased consecutively by BMI group (BMI $<25,25-30$ and $>30 \mathrm{~kg} \mathrm{~m}^{-2}$, Fig. 1), and the proportion of underreporters increased by BMI group from $32 \%$, to $52 \%$ and $75 \%$ of men $(P=0.07)$ and from $33 \%$, to $62 \%$ and $92 \%$ of women $(P<0.001)$, respectively (cf. Table 2). In fact, the average FIL (0.89) for the 16 most obese respondents $\left(\mathrm{BMI}>30 \mathrm{~kg} \mathrm{~m}^{-2}\right.$ ) was lower than their estimated BMR.

Smokers and former smokers had similar FIL, but both groups had lower FIL than non-smokers $(P<0.05$, Fig. 1$)$. Consequently, the proportion of underreporters was 
Table 2 Proportion (\%) of underreporters by 24-hour recalls after stratification for gender, BMI (body mass index), smoking habit, age education level or area of living. Two cut-off levels were applied for FIL (food intake level, equivalent to reported energy intake/estimated basal metabolic rate)

\begin{tabular}{|c|c|c|}
\hline \multirow[b]{2}{*}{ Strata } & \multicolumn{2}{|c|}{ Underreporters (\%) } \\
\hline & $\mathrm{FIL}<1.2^{*}$ & FIL < 1.35† \\
\hline \multicolumn{3}{|l|}{ Gender } \\
\hline Men $(n=94)$ & 44 (NS) & 61 (NS) \\
\hline Women $(n=99)$ & 47 & 72 \\
\hline \multicolumn{3}{|l|}{$\mathrm{BMI}\left(\mathrm{kg} \mathrm{m}^{-2}\right)$} \\
\hline$<25(n=105)$ & $32(P<0.001)$ & $53(P<0.001)$ \\
\hline $25-30(n=32)$ & 56 & 79 \\
\hline$>30(n=16)$ & 88 & 94 \\
\hline \multicolumn{3}{|l|}{ Smoking habitł } \\
\hline Non-smoker $(n=89)$ & $37(P<0.01)$ & $78(P<0.01)$ \\
\hline Former smoker $(n=32)$ & 44 & 80 \\
\hline Smoker $(n=40)$ & 68 & 57 \\
\hline \multicolumn{3}{|l|}{ Age } \\
\hline 30 years $(n=50)$ & $26(P<0.01)$ & $40(P<0.001)$ \\
\hline 40 years $(n=48)$ & 58 & 75 \\
\hline 50 years $(n=47)$ & 45 & 77 \\
\hline 60 years $(n=48)$ & 54 & 75 \\
\hline \multicolumn{3}{|l|}{ Education level } \\
\hline High $(n=106)$ & 40 (NS) & $59(P<0.06)$ \\
\hline Low $(n=87)$ & 50 & 72 \\
\hline \multicolumn{3}{|l|}{ Area of living } \\
\hline Urban $(n=98)$ & 44 (NS) & 64 (NS) \\
\hline Rural $(n=95)$ & 47 & 68 \\
\hline
\end{tabular}

${ }^{*} \mathrm{FIL}<1.2$ corresponds to a PAL for a chair-bound or bed-bound person (survival limit).

$\dagger \mathrm{FIL}<1.35$ corresponds to a PAL for the lowest possible free-living sedentary lifestyle.

$\ddagger$ Non-smokers using snuff are not included

$P$ values obtained with $\mathrm{chi}^{2}$-testing among the groups. NS=not significant.

lower among non-smokers (37\%), but, interestingly, also among former smokers (44\%) compared with smokers (68\%, $P<0.01$, Table 2). Smokers, former smokers and non-smokers had similar BMI (Fig. 1), but smokers reported lower energy intake than former smokers and non-smokers $(P<0.05$; data not shown).

Respondents with less than 10 years at school had slightly lower average FIL (1.20 (0.32)) than those with a higher educational level $(1.28(0.34)), P=0.08$, but the

Table 3 Linear regression models for variables associated with FIL in men and women combined

\begin{tabular}{lcccc}
\hline Variable* & Parameter† estimate & SE & $P$ value & Partial $R^{2}(\%)$ \\
\hline BMl & -0.039 & 0.006 & $<0.001$ & 23.5 \\
Age & -0.063 & 0.020 & $<0.01$ & 4.6 \\
Smoking & 0.064 & 0.027 & $<0.05$ & 2.5 \\
\hline
\end{tabular}

* BMI, age, smoking habit, area of living and gender were entered into the model. Variables are listed in the order they were introduced into the model. No other variable met the 0.05 significance level for entry into the model. † Parameter estimate=regression coefficient.

$\mp$ Standard error (SE) of the regression coefficient.

$\S$ When energy intake was added to the model as independent variable, reported energy intake explained $72.2 \%$ of the variation in FIL, BMI another $9.1 \%$, and smoking and age group each $0.4 \%$. proportion of underreporters did not differ significantly (50\% and 40\%, respectively, Table 2). Respondents with higher education were leaner than those with lower education (BMI: 24.2 (3.0) and 25.8 (3.5) $\mathrm{kg} \mathrm{m}^{-2}$, respectively, $P<0.01$ ), but their average recorded energy intakes were similar (data not shown). Reporting of food intake was unrelated to gender (Fig. 1), area of living, and day of interview (data not shown).

A stepwise multiple linear regression, employing FIL as dependent variable and BMI, age, smoking habit, gender, area of living and education as independent variables, confirmed high BMI $(P<0.001)$, high age $(P<0.01)$ and smoking habit $(P<0.05$, Table 3$)$ to be independently associated with underreporting of food intake.

\section{Composition of the diet at different levels of FIL}

Underreporters $(\mathrm{FIL}<1.2)$ reported a significantly higher intake of protein per energy unit, but a lower intake of fat and sucrose than respondents with FIL $>1.35$ ('credible intake') (Table 4). Density of other nutrients, e.g. carbohydrates, fibre, vitamin $\mathrm{C}$, etc. and alcohol, did not differ significantly between the groups.

Intake frequencies and recorded portion sizes for 80 single food items were compared between respondents with FIL $<1.2$ and FIL $\geq 1.2$ (data not shown). Respondents with FIL $<1.2$ reported significantly lower intake frequencies for 24 out of the 80 food items. Thus, the intake frequencies of most evaluated sweet products and breads, and 'high-fat' products, such as sandwich spread with 80\%, milk with 3\% and cheese with 28\% fat, sausages, bacon, crisps and alcohol, were significantly lower in underreporters than in others. The numbers of recorded intakes in 10 food groups of clustered food items were compared between men and women, respectively, with FIL below or above 1.2 (Table 5). In general, both male and female underreporters reported fewer intakes per day in nearly all food groups (up to $-39 \%)$. The difference was highly significant for both men and women for fats on bread, bread/cereals and sweets. In addition, underreporting men had significantly fewer intakes of fruits and meat, and women of dairy products, potato/rice/pasta and alcoholic beverages.

In order to understand the nature of the lower intake frequencies in underreporters - e.g. if it reflected that underreporters avoided an item or if they only ate it less frequently, proportions reporting consumption were compared as well as their intakes (i.e. respondents reporting consumption on at least one of the recall days versus no consumption). The explanation for lower frequencies in those with FIL $<1.2$ was complex. For some items it mainly reflected underreporters avoiding the item, such as high-fat milk, mashed potatoes and high-fat spread on bread (Bregott), fruit syrup, soft drinks, juice and crisps (all $P<0.01$ ). For other items the lower frequency reflected eating it less frequently, such as white bread, high-fat cheese, sausage on sandwich and various 


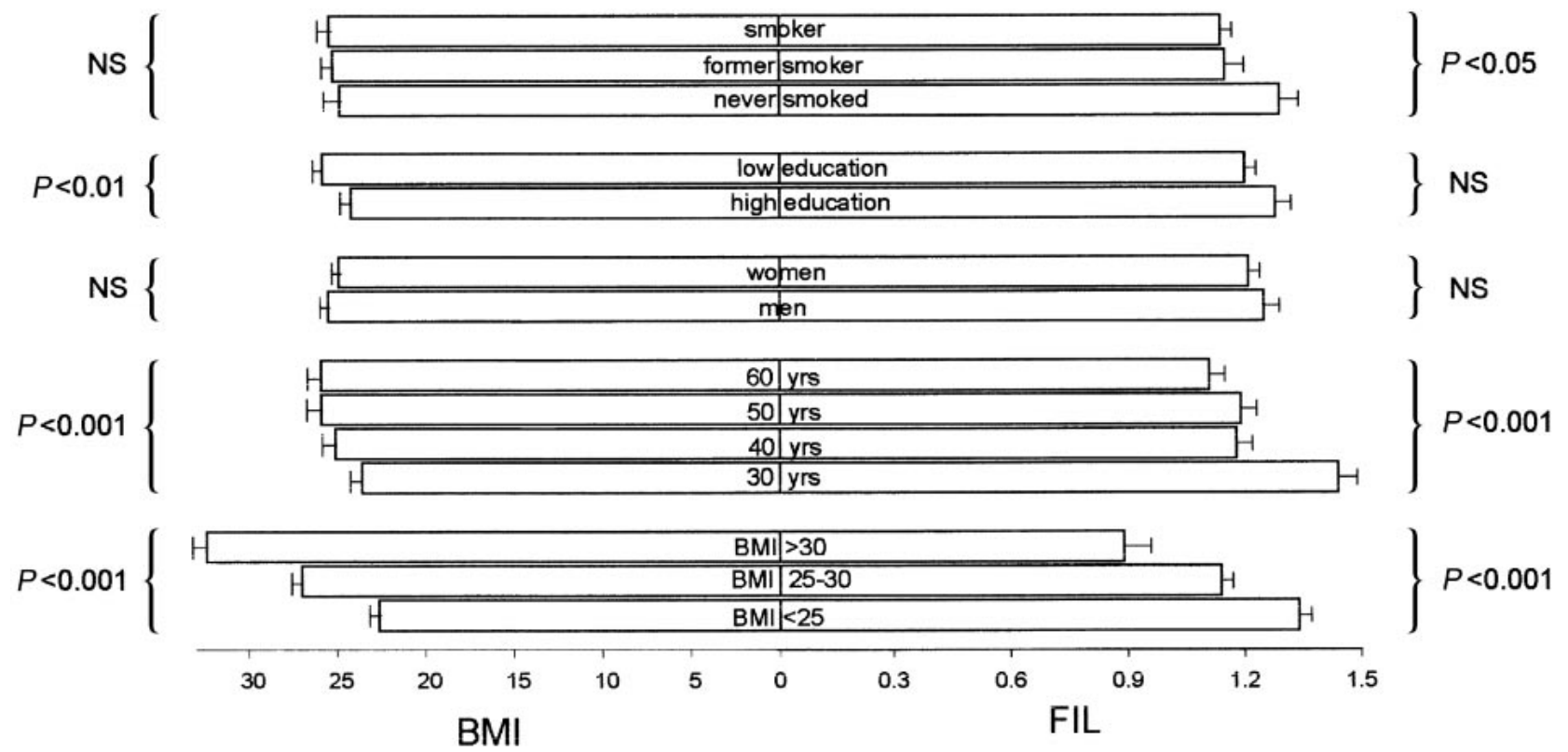

Fig. 1 Horizontal bar chart displaying average FIL (food intake level, equivalent to reported energy intake/estimated basal metabolic rate) to the right and BMI (body mass index, $\mathrm{kg} \mathrm{m}^{-2}$ ) to the left in groups stratified for smoking habit, educational level, gender, age and body mass index. In total, 193 30- to 60-year-old men and women in Northern Sweden were studied

sweet items (all $P<0.01$ ). In addition, consumers with FIL $<1.2$ reported smaller portion sizes of most food items ( 45 out of 80 food items differed by more than $10 \%$ ); 13 of these items differed significantly. Smaller portion sizes were most evident for high-fat foods, such as butter, cheese with 28\% fat, fried potatoes, liver paste and pancakes. However, a striking exception (larger portion sizes) was reported for some 'healthy foods', such as frozen mixed vegetables, spinach, cabbage, root vegetables, oranges, porridge from wholemeal, bran flakes, fatty fish, shell fish, and blood-based foods, although statistical significance was not reached for all of these items.

\section{Discussion}

The present study confirms that underreporting is common, and unevenly distributed in the population, when diet exposure is assessed by 24-hour recalls. Thus, for more than $40 \%$ of the respondents, the recorded energy intake fell below BMR. Besides the confirmation of a strong relation between underreporting of food intake and high BMI, we demonstrated that old age and smoking habits co-varied with underreporting. In contrast, gender, area of living and level of education did not bias food recording in the North Swedish population. In addition,

Table 4 Composition of the diet at different levels of FIL (food intake level, equivalent to reported energy intake/estimated basal metabolic rate). Data are expressed as mean (standard deviation (SD))

\begin{tabular}{|c|c|c|c|c|}
\hline & \multicolumn{3}{|c|}{ FIL } & \multirow{2}{*}{$\begin{array}{l}\text { ANOVA } \\
P \text { value }\end{array}$} \\
\hline & $<1.2(n=88)$ & $1.2-1.35(n=40)$ & $>1.35(n=65)$ & \\
\hline Energy (MJ) & $6.2(1.4)^{a, b}$ & $8.1(1.4)^{a, c}$ & $10.3(2.0)^{b, c}$ & $<0.001$ \\
\hline Protein (g/10 MJ) & $97(15)^{a}$ & $92(11)$ & $86(10)^{a}$ & $<0.001$ \\
\hline Fat $(g / 10 \mathrm{MJ})$ & $90(11)^{a}$ & $93(13)$ & $97(9)^{a}$ & $<0.01$ \\
\hline Carbohydrates (g/10 MJ) & $282(27)$ & $275(35)$ & $278(29)$ & NS \\
\hline Sucrose $(g / 10 \mathrm{MJ})$ & $50(20)^{a}$ & $45(13)^{b}$ & $57(16)^{a, b}$ & $<0.01$ \\
\hline Fibre $(\mathrm{g} / 10 \mathrm{MJ})$ & $21(5)$ & $21(6)$ & $20(5)$ & NS \\
\hline Vitamin C (mg/10 MJ) & $87(52)$ & $84(42)$ & 79 (42) & NS \\
\hline Vitamin $D(\mu \mathrm{g} / 10 \mathrm{MJ})$ & 7.6 (3.2) & $7.5(2.2)$ & $6.8(2.2)$ & NS \\
\hline Vitamin $E(\mu \mathrm{g} / 10 \mathrm{MJ})$ & $9.3(2.4)$ & $9.0(1.6)$ & $9.1(2.0)$ & NS \\
\hline$\beta$-Carotene $(\mathrm{mg} / 10 \mathrm{MJ})$ & $3.5(3.1)$ & $3.4(2.6)$ & $2.6(1.6)$ & NS \\
\hline Calcium (mg/10 MJ) & $1249(312)$ & $1198(262)$ & $1171(233)$ & NS \\
\hline Alcohol (g/10 MJ) & $7.5(10.4)$ & $10.9(11.3)$ & $7.7(10.0)$ & NS \\
\hline
\end{tabular}

\footnotetext{
${ }^{a-c}$ Numbers (within a line) sharing the same superscript differ significantly, by at least $P<0.05$, when tested with a multiple mean test (Tukey's test) applied after the ANOVA had indicated a significant difference among the groups.
}

$\mathrm{NS}=$ not significant. 

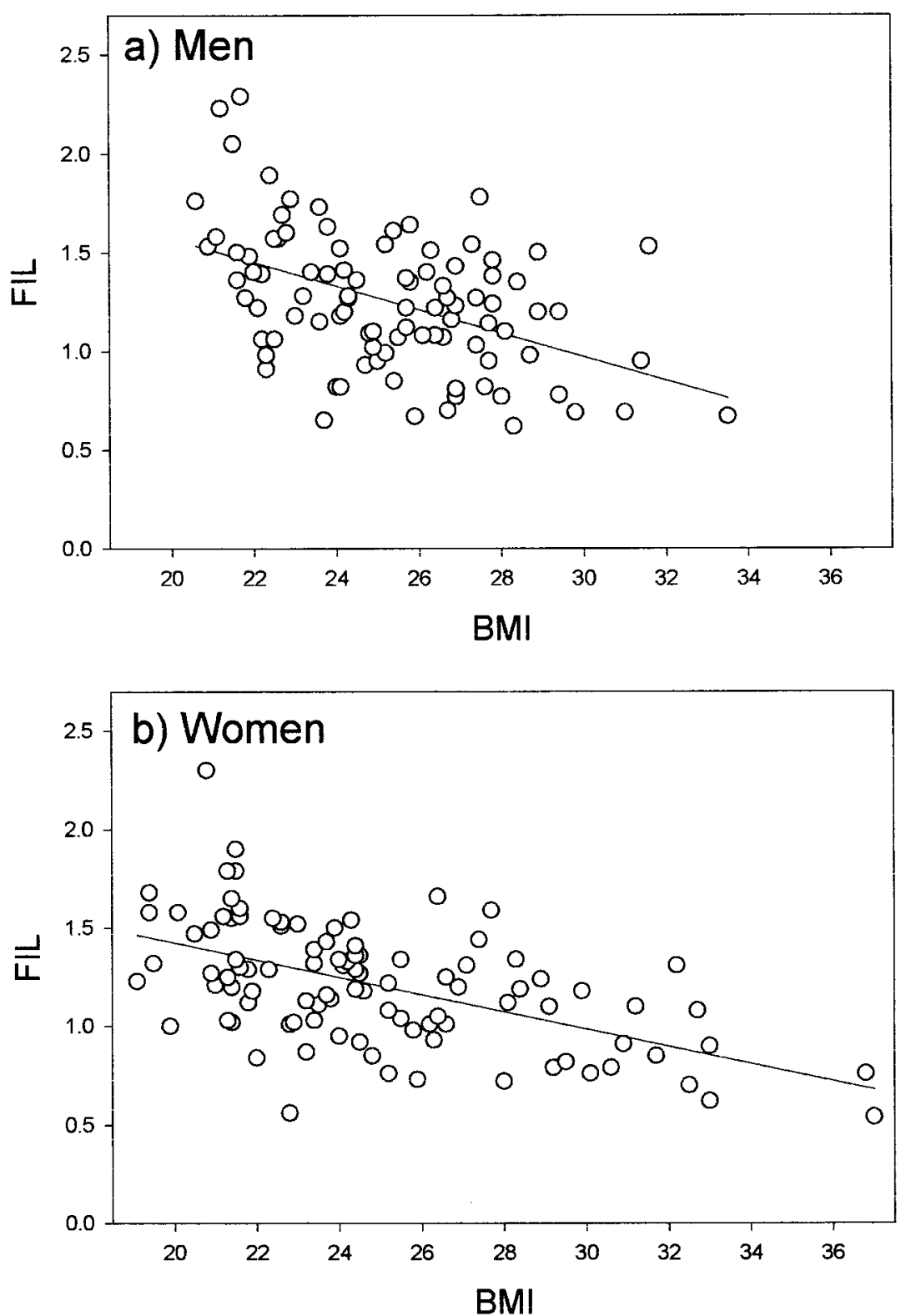

Fig. 2 Plot of FIL (food intake level, equivalent to reported energy intake/estimated basal metabolic rate) versus BMI (body mass index, $\mathrm{kg} \mathrm{m}^{-2}$ ) in (a) 93 men and (b) 99 women in Northern Sweden. The linear regression curve is displayed. The Pearson correlation coefficients were -0.47 for men and -0.55 for women (both $P<0.01$ )

we demonstrated that the 'pattern' of underreporting by 24-hour recalls was complex, i.e. a mixture of avoiding food items, reporting lower intake frequencies and smaller portion sizes, but also a contrasting overreporting of portion sizes for some items. However, when having relatively small numbers of participants in each group, one should be cautious when interpreting the results.

Energy intakes not reaching true intakes may reflect a 'poor' interview technique, or inability or 'unwillingness' of respondents to report intakes given that databases are considered correct. The fact that potential factors other than underreporting per se have contributed to low levels of recorded energy intakes can certainly not be excluded in the present study, but the following argues for a 'true' underreporting. (1) Respondents were interviewed 10 times over the telephone due to the vast distances in Northern Sweden. We cannot evaluate the fact that the 24hour recalls were obtained over the telephone, but conclude that 'our' proportion of underreporting was similar to what was reported in other studies employing 24-hour recalls ${ }^{30,31}$. (2) The interviewers had been calibrated and they also rotated randomly among respondents. In a previous study on middle-aged men and women, the FIL values decreased when 24-hour recalls were repeated ${ }^{31}$. This was not the explanation for the low average energy intakes in the present study since 
Table 5 Reported number of daily intakes in food groups for respondents with FIL $\geq 1.2$ and FIL $<1.2$

\begin{tabular}{|c|c|c|c|c|c|c|}
\hline \multirow[b]{2}{*}{ Food group } & \multicolumn{3}{|c|}{ Men } & \multicolumn{3}{|c|}{ Women } \\
\hline & $\begin{array}{c}\mathrm{FIL} \geq 1.2 \dagger \\
(n=53)\end{array}$ & $\begin{array}{c}\mathrm{FIL}<1.2 \dagger \\
(n=41)\end{array}$ & $\begin{array}{c}\text { Difference } \\
(\%)\end{array}$ & $\begin{array}{c}\mathrm{FIL} \geq 1.2 \dagger \\
(n=52)\end{array}$ & $\begin{array}{c}\mathrm{FIL}<1.2 \dagger \\
(n=47)\end{array}$ & $\begin{array}{c}\text { Difference } \\
(\%)\end{array}$ \\
\hline Fat on bread & 2.4 & $1.7^{\star *}$ & -29 & 2.3 & $1.5^{\star \star \star}$ & -35 \\
\hline Dairy products & 3.1 & 2.8 & -12 & 3.3 & $2.4^{\star \star \star}$ & -27 \\
\hline Bread/cereals & 3.9 & $3.0^{\star \star \star}$ & -22 & 3.7 & $2.7^{\star \star \star}$ & -27 \\
\hline Fruits & 0.8 & $0.5^{\star \star}$ & -38 & 1.2 & 1.0 & -17 \\
\hline Vegetables & 0.9 & 0.7 & -21 & 1.2 & 1.0 & -19 \\
\hline Potato/rice/pasta & 1.0 & 0.9 & -10 & 0.9 & $0.8^{*}$ & -12 \\
\hline Meat & 1.1 & $0.9^{*}$ & -21 & 0.9 & 0.8 & -7 \\
\hline Fish & 0.3 & 0.3 & -7 & 0.3 & 0.2 & -31 \\
\hline Sweets & 4.1 & $2.7^{\star \star \star}$ & -34 & 3.4 & $2.5^{\star \star}$ & -26 \\
\hline Alcoholic beverages & 0.5 & 0.4 & -31 & 0.3 & $0.2^{*}$ & -39 \\
\hline
\end{tabular}

† FIL $<1.2$ corresponds to a PAL for a chair-bound or bed-bound person (survival limit).

$\ddagger$ Difference in mean reported number of intakes between respondents with FIL $<1.2$ and FIL $\geq 1.2$ in per of intake for respondents with FIL $\geq 1.2$.

${ }^{\star * *}, P<0.001 ;{ }^{\star *}, P<0.01 ;{ }^{*}, P<0.05$.

there was no significant difference between the days of interview. Neither could we explain the low energy intakes by differences in interviewers. (3) The illustrations used for portion size estimations have previously been validated, and it was concluded that differences between served and estimated amounts of foods and subsequent under- and overestimation of single food items were eliminated when several meals were evaluated in a series $^{24}$. Therefore, the portion model is not likely to have biased the recordings largely.

Black et al. found in a review of dietary surveys that nine out of ten 24-hour recalls were physiologically unlikely to be true within some specified statistical conditions $^{22}$. The present confirmation of the difficulties of achieving plausible energy intakes with 24-hour recalls, reflected by the high proportion of both men and women with FIL values below even liberal cut-off levels, supports the hypothesis that only certain people with a welldeveloped episodic memory bank are suitable to perform 24-hour recalls ${ }^{32}$. In general, recall is better when the permanent memory bank can be employed ${ }^{32}$. This hypothesis is also supported by the review of Black et $a l^{22}$, since dietary history methods were more likely to be true than other recall methods. However, biased food recording is not limited to recall of past diets but occurs with all dietary assessment methods, indicating involvement of subject-specific underreporting too. This may be related to biological factors, such as body weight, or psychosocial factors, such as social desirability ${ }^{15}$.

In agreement with several other studies ${ }^{3-8}$, we found univariate negative correlations between energy intake and BMI, and accordingly between FIL and BMI. In multivariate modelling BMI explained $9 \%$ of the variation in FIL among respondents, whereas smoking and age added less than $1 \%$ to the $72 \%$ explained by recorded energy intake. Therefore, BMI seems to be one of the most consistent factors confounding recording of food intake level and prediction of underreporting. This calls for special attention when dietary surveys are performed on obese people, such as those employing biomarkers as internal standard, or when dietary intakes are compared between groups with different BMI, such as matching for BMI. It also emphasises the importance of including BMI as a confounder when various lifestyle factors are related to diet intake. However, it should be remembered that even though weight consciousness and a desire to lose weight are important factors for predicting underreporting, the highest number of underreporters are found among subjects of normal weight ${ }^{3}$.

The present data indicate smokers to be slightly more likely than others to have a biased recording of food intake. Our finding of smokers having lower average FIL value than non-smokers is consistent with some reports $^{8,33}$, but not others ${ }^{3}$. Smokers' lower FIL value in the present study could not be explained by differing BMI. Optional explanations for lower FIL in smokers are lower energy expenditure or underreporting per se. The following argues for the latter explanation: (1) smoking is considered to enhance, not reduce, energy metabolism; and (2) no indication of a lower physical activity level among smokers than non-smokers was found as estimated by six questions about physical activity at work and leisure. Since smoking is also reported to change food preferences and appetite ${ }^{34}$, caution should be taken when evaluating dietary habits in smokers.

The numbers of reported intakes were generally lower, and the portion sizes smaller, for the group with low FIL value compared with the group with higher FIL value. However, in accordance with other studies ${ }^{2,3,35}$, the former group frequently reported larger portion sizes for socially desirable food items, although not consistently statistically significant. The combined pattern of numbers of reported intakes, total avoidance of the food item or reporting smaller portion sizes indicated that underreporters 'forgetting' food intake occasions was a larger problem than 'reducing' portion sizes for low recorded energy intake levels and FIL values. This is probably a greater problem for foods rich in fat and sucrose $e^{3,4,36}$, as indicated by the low density of these components in the low FIL group. In order to better understand the nature of 
biased food recording and take appropriate measures, more studies providing detailed characterisation of individuals with a low FIL value when recording of meals and snacks are omitted, and the cause of omissions, are needed. One way to extend the present knowledge would be to look into the role of behaviour factors on food recording. For instance, Taren et al. identified psychosocial factors, such as social desirability and selfimage of body shape, to be important factors to predict underreporting ${ }^{15}$.

The major conclusions of this study, also confirmed by other studies, are that it seems extremely difficult to obtain plausible energy intakes with 24-hour recalls and differential underreporting seems obvious. The problems discussed in this study call the method into question. Can it be improved or should it be abandoned?

\section{Acknowledgements}

This study was supported by the Swedish Cancer Society. We would like to thank Dr Allan Hackett for fruitful discussions, and Ulla-Stina Spetz, Karin Andrén, Margareta Holmgren, Margareta Jonsson, Åsa Lindblad, Jeanette Sigurdh, Lena Eriksson and Kristina Stefanowich for performing the 24-hour recalls.

\section{References}

1 Black AE, Bingham SA, Johansson G, Coward WA. Validation of dietary intakes of protein and energy against 24 hour urinary $\mathrm{N}$ and DLW energy expenditure in middle-aged women, retired men and post-obese subjects: comparison with validation against presumed energy requirements. Eur. J. Clin. Nutr. 1997; 51: 405-13.

2 Johansson G, Åkesson A, Berglund M, Nermell B, Vahter M. Validation with biological markers for food intake of a dietary assessment method used by Swedish women with three different dietary preferences. Public Health Nutr. 1998; 1(3): 199-206.

3 Johansson L, Solvoll K, Björneoe GE, Drevon CA. Under- and overreporting of energy intake related to weight status and lifestyle in a nationwide sample. Am. J. Clin. Nutr. 1998; 68: 266-74.

4 Rothenberg E, Boseaus I, Steen B. Evaluation of energy intake estimated by a diet history in three free-living 70 year populations in Gothenburg, Sweden. Eur. J. Clin. Nutr. 1997; 51: 60-6.

5 Stallone DD, Brunner EJ, Bingham SA, Marmot MG. Dietary assessment in Whitehall II: the influence of reporting bias on apparent socioeconomic variation in nutrient intakes. Eur. J. Clin. Nutr. 1997; 51: 815-25.

6 Hirvonen T, Männistö S, Roos E, Pietinen P. Increasing prevalence of underreporting does not necessarily distort dietary surveys. Eur. J. Clin. Nutr. 1997; 51: 297-301.

7 Bandini LG, Schoeller DA, Cyr HN, Dietz WH. Validity of reported energy intake in obese and nonobese adolescents. Am. J. Clin. Nutr. 1990; 52: 421-5.

8 Ballard-Barbash R, Graubard I, Krebs-Smith SM, Schatzkin A, Thompson FE. Contribution of dieting to the inverse association between energy intake and body mass index. Eur. J. Clin. Nutr. 1996; 50: 98-106.

9 Gross J, Rosen JC, Leitenberg H, Willmuth ME. Validity of the eating attitudes test and the eating disorders inventory in bulimia nervosa. J. Consulting Clin. Psychol. 1986; 54: 875-6.

10 Ruderman AJ. Dietary restraint: a theoretical and empirical review. Psychological Bull. 1986; 99: 247-62.

11 Wear RW, Pratz O. Test-retest reliability for the Eating Disorder Inventory. Int. J. Eating Disorders 1987; 6: 767-9.

12 Welch G, Hall A, Norring C. The factor structure of the Eating Disorder Inventory in a patient setting. Int. J. Eating Disorders 1990; 9: 79-85.

13 Klesges RC, Klem ML, Epkins CC, Klesges LM. A longitudinal evaluation of dietary restraint and its relationship to changes in body weight. Addictive Behav. 1991; 16: 363-8.

14 Weinberger DA, Schwartz GE, Davidson RJ. Low-anxious, high-anxious, and repressive coping styles: psychometric patterns and behavioral and physiological responses to stress. J. Abnorm. Psychol. 1979; 88: 369-80.

15 Taren DL, Tobar M, Hill A, Howell W, Shisslak C, Bell I, Ritenbaugh C. The association of energy intake bias with psychological scores of women. Eur. J. Clin. Nutr. 1999; 53 570-8.

16 Blundell JE. What foods do people habitually eat? A dilemma for nutrition, an enigma for psychology. Am. J. Clin. Nutr. 2000; 71: 3 .

17 Birkett NJ. Intake of fruits and vegetables in smokers. Public Health Nutr. 1999; 2: 217-22.

18 Walmsley CM, Bates CJ, Prentice A, Cole TJ. Relationship between cigarette smoking and nutrient intakes and blood status indices of older people living in the UK: further analysis of data from the National Diet and Nutrition Survey of people aged 65 years and over, 1994/95. Public Health Nutr. 1999; 2: 199-208.

19 Morabia A, Wynder EL. Dietary habits of smokers, people who never smoked, and ex-smokers. Am.J. Clin. Nutr. 1990; 52: 933-7.

20 Block G, Patterson B, Subar A. Fruit, vegetable, and cancer prevention: a review of the epidemiological evidence. Nutr. Cancer 1992; 18: 1-29.

21 Bathalon GP, Tucker KL, Hays NP, Vinken AG, Greenberg AS, Crory MA, Roberts SB. Psychological measures of eating behavior and the accuracy of 3 common dietary assessment methods in healthy postmenopausal women. Am. J. Clin. Nutr. 2000; 71: 739-45.

22 Black AE, Goldberg GR, Jebb SA, Livingstone MBE, Prentice AM. Critical evaluation of energy intake data using fundamental principals of energy physiology: 2. Evaluating the results of dietary surveys. Eur. J. Clin. Nutr. 1991; 45: 583-99.

23 Weinehall L, Westman G, Hellsten G, Boman K, Hallmans G, Pearson TA, Wall S. Shifting the distribution of risk: results of a community intervention in a Swedish program for the prevention of cardiovascular disease. J. Epidemiol. Community Health 1999; 53: 243-50.

24 Håglin L, Hagman U, Nilsson $M$. Evaluation of the meal model 'matmallen'. A means of estimating consumed amounts of food. Scand. J. Nutr. 1995; 39: 79-83.

25 Bergström L, Kylberg E, Hagman U, Eriksson H, Bruce A. The food composition data base system (KOST-systemet) - its use for nutrient values. Vår Föda 1991; 43: 439-47.

26 James WPT, Ferro-Luzzi A, Waterlow JC. Definition of chronic energy deficiency in adults. Report of a working party of the International Dietary Energy Consultancy Group. Eur. J. Clin. Nutr. 1988; 42: 969-81.

27 Department of Health. Dietary Reference Values for Food Energy and Nutrients for the United Kingdom. Report on Health and Social Subjects. London: HMSO, 1991.

28 Black AE, Coward WA, Cole TJ, Prentice AM. Human energy expendiure in affluent societies: an analysis of 574 doubly labelled water measurements. Eur. J. Clin. Nutr. 1996; 50: 72-92.

29 Goldberg GR, Black AE, Jebb SA, Cole TJ, Murgatroyd PR, 
Coward WA, Prentice AM. Critical evaluation of energy intake data using fundamental principals of energy physiology: 1 . Derivation of cut-off limits to identify under-recording. Eur.J. Clin. Nutr. 1991; 45: 569-81.

30 Black AE. Critical evaluation of energy intake using the Goldberg cut-off for energy intake:basal metabolic rate. A practical guide to its calculation, use and limitations. Int. J. Obesity 2000; 24: 1119-30.

31 Johansson G, Callmer C, Gustafsson J-A. Validity of repeated dietary measurements in a dietary intervention study. Eur. J. Clin. Nutr. 1992; 46: 717-28.

32 Smith AF. Cognitive psychological issues of relevance to the validity of dietary reports. Eur. J. Clin. Nutr. 1993; 47(Suppl. 2): S6-18.
33 Pryer JA, Vrijheid M, Nichols R, Kiggins M, Elliot P. Who are the low energy reporters in the dietary and nutritional survey of British adults? Int. J. Epidemiol. 1997; 26: 146-54.

34 Moffat RJ, Owens SG. Cessation from cigarette smoking: changes in body weight, body composition, resting metabolism and energy consumption. Metabolism 1991; 40: 465-70.

35 Poppit SD, Swann D, Black AE, Prentice AM. Assessment of selective underreporting of food intake by both obese and non-obese women in a metabolic facility. Int. J. Obesity 1998; 22: $303-11$

36 Goris AHC, Westerterp-Plantenga MS, Westerterp KR. Undereating and underrecording of habitual food intake in obese men: selective underreporting of food intake. Am. J. Clin. Nutr. 2000; 71: 130-4. 